\title{
Correction to: Visual-Syntactic Text Formatting: Developing EFL Learners' Reading Fluency Components
}

\author{
Wei Gao ${ }^{1}$ Ehsan Namaziandost ${ }^{2,3}$ (D) Mohammad Awad Al-Dawoody Abdulaal $^{4}$
}

Published online: 22 December 2021

(c) Springer Science+Business Media, LLC, part of Springer Nature 2021

\section{Correction to: Journal of Psycholinguistic Research https://doi.org/10.1007/s10936-021-09823-x}

The original version of the article has contains errors in paragraph 3 in page no. 12 and the missing 5th affiliation has been included to the third author (Mohammad Awad AlDawoody Abdulaal).

Original article has been revised.

Publisher's Note Springer Nature remains neutral with regard to jurisdictional claims in published maps and institutional affiliations.

The original article can be found online at https://doi.org/10.1007/s10936-021-09823-x.

Ehsan Namaziandost

e.namazi75@yahoo.com

Wei Gao

uugycga6262002@163.com

Mohammad Awad Al-Dawoody Abdulaal ma.abdulaal@psau.edu.sa

1 College of Teacher Education, Taishan University, Shandong 271000, China

2 University of Applied Science and Technology (UAST), Khuzestan, Iran

3 Mehrarvand Institute of Technology, Abadan, Iran

4 Department of English, College of Sciences and Humanities, Prince Sattam Bin Abdulaziz University, Al-Kharj, Saudi Arabia 